\title{
Glistenings in hydrophobic acrylic intraocular lenses do affect visual function
}

This article was published in the following Dove Press journal:

Clinical Ophthalmology

26 November 2013

Number of times this article has been viewed

\section{George HH Beiko ${ }^{1,2}$ \\ Andrzej Grzybowski ${ }^{3,4}$}

'Department of Surgery, McMaster University, Hamilton, ON, Canada; ${ }^{2}$ Department of Ophthalmology and Vision Sciences, University of Toronto, Toronto, ON, Canada; ${ }^{3}$ Department of Ophthalmology, University of Warmia and Mazury, Olsztyn, Poland, ${ }^{4}$ Department of Ophthalmology, Poznan City Hospital, Poznan, Poland
Correspondence: George HH Beiko I80 Vine St., Ste 103, St. Catharines, ON, Canada, L2R 7P3

Email georgebeiko@hotmail.com

\section{Dear editor}

We recently read the paper "Evaluation of in vitro glistening formation in hydrophobic acrylic intraocular lenses" by Thomes and Callaghan. ${ }^{1}$ The paper is extremely interesting in that the authors, employees of Alcon Research Ltd (Forth Worth, TX, USA), report not only that Alcon lenses have glistenings, but also that "continuous improvements on glistening formation" have been made by Alcon over the years from 2003 to 2012. We congratulate the authors and Alcon on their efforts, and on making this admission.

The paper raises a number of concerns and questions. Firstly, the statement in the introduction, "Glistenings are typically observed within a few months of surgery and plateau approximately 1 year after surgical implantation of the [intraocular lens] IOL"1 is not referenced. The reported literature is in contradiction to this statement, in that the glistenings formation, as well as the severity of glistenings, has been reported to increase with longer follow-up times. ${ }^{2-8}$ Very few studies that evaluate the progression beyond one year find glistening formation to be stable. ${ }^{9-10}$ In addition, this statement is contradicted by the authors themselves in the introduction section of this paper where they state that a study by Colin et al ${ }^{4}$ found that $73.8 \%$ of the IOLs had glistenings when follow-up was less than 2 years, and $94.2 \%$ of the IOLs had glistenings when the follow-up was longer than 2 years. Even after 10 years of follow-up, no plateau was seen. ${ }^{2}$

In the Introduction, the authors state that "These results are consistent with most studies regarding glistening formation in AcrySof ${ }^{\circledR}$ IOLs that found no impact on visual function."' This statement is incorrect. Although Snellen visual acuity is only affected by severe grades of glistenings, visual function is affected earlier. Six published papers examined the effect of glistenings on contrast sensitivity (CS). Four of these studies reported that glistenings had a significant negative effect on the high spatial frequency of CS, ${ }^{3,11-13}$ and two studies were inconclusive. ${ }^{9,10}$ While some studies do show a decrease in visual acuity with increased severity of glistenings, ${ }^{4,13}$ the general consensus in the literature tends to be that visual acuity is unaffected by glistening. In vitro studies report a positively correlated relationship between the total integrated light scatter and the severity of glistenings. ${ }^{14,15}$ Also, several in vivo studies found increased levels of intraocular stray light. ${ }^{16-18}$ This analysis is published in van der Mooren et al. ${ }^{19}$

The authors state that continuous improvements "... include the implementation of advanced manufacturing equipment, improved environmental controls, and tightened process controls/specifications. Specific details of these improvements cannot be fully disclosed due to the proprietary nature of the IOL manufacturing process." ${ }^{\text {"1 }}$ This is 
curious as any alterations or modifications to the material or manufacturing process have to be submitted to and approved by government agencies.

Because contradictory information exists in the literature concerning glistenings it would be helpful, in order to understand the relevance of these measurements, to know when the authors feel that impactful changes were made to the manufacturing process of Acrysof lenses. In a recent paper by van der Mooren et al, ${ }^{19}$ the authors report measurements performed on Acrysof lenses very recently produced for the Japanese market following the supposed manufacturing changes alluded to in this paper by Thomes and Callaghan. ${ }^{1}$ Improvements were not evident in this paper as the most recently manufactured Acrysof IOLs had glistening formation and straylight values that can be considered typical when compared to historical measurements of Acrysof lenses. Additionally, straylight values of these lenses were considerably higher than those without significant glistenings.

With respect to the Acrysof lenses from 2003, the following statement in the Methods section is not supported or referenced, "Internal studies on the glistening response and storage conditions with AcrySof have shown that glistening formation will not be induced if samples are stored within these temperature and relative humidity ranges." ${ }^{\prime 1}$ Additionally, the US Food and Drug Administration suggests a shelf life of 5 years for intraocular lenses $;{ }^{20}$ thus, it is incumbent upon the authors to ensure that the older Acrysof lenses had not deteriorated in any way and to provide this proof.

Although the authors reference a published method for accelerated microvacuole formation, ${ }^{15}$ they have chosen to employ another technique. An explanation as to why this was done and justification for their method should be given. Without published references, it is not possible to view or compare the results of this study with other data in the literature.

It would have been extremely relevant for the authors to include lenses of other materials in the assessment, similar to Tognetto et al, ${ }^{7}$ as not all materials respond in the same way to glistening formation. It should be stressed that hydrophobic acrylic IOLs from different manufacturers do not have similar glistening formation, ${ }^{19}$ so that the relative amount of glistening formation could have been critically assessed if all were tested by the same protocol.

In summary, the conclusions made by the authors cannot be substantiated as the methods used to draw these conclusions have not been fully validated in the paper. In spite of this, the concern of the authors and their employer, Alcon Research Ltd, for glistening formation is to be lauded and encouraged to continue until the lenses are truly glistening free.

\section{Disclosure}

The authors report no conflicts of interest in this communication.

\section{References}

1. Thomes BE, Callaghan TA. Evaluation of in vitro glistening formation in hydrophobic acrylic intraocular lenses. Clin Ophthalmol. 2013;7:1529-1534.

2. Behndig A, Mönestam E. Wuantification of glistenings in intraocular lenses using Scheimpflug phtography. J Cat Refract Surg. 2009;35:14-17.

3. Waite A, Faulkner N, Olson RJ. Glistenings in the single-piece, hydrophobic, acrylic intraocular lenses. Am. J. Ophthalmol. 2007;144(1):143-144.

4. Colin j, Praud,Touboul DD, Schweitzer C. Incidence of glistenings with the latest generation of yellow-tinted hydrophobic acrylic intraocular lenses. J. Cataract Refract. Surg. 2012;38(7):1140-1146.

5. Moreno-Montañés J, Alvarez A, Rodríguez-Conde R, FernándezHortelano A. Clinical factors related to the frequency and intensity of glistenings in AcrySof intraocular lenses. J. Cataract Refract. Surg. 2003;29(10):1980-1984.

6. Peetermans E, Hennekes R. Long-Term Results of Wagon Wheel Packed Acrylic Intraocular lenses (AcrySof). Bull Soc. BelgeOphtalmol. 1999;271:45-48.

7. Tognetto D, Toto L, Sanguinetti G, Ravalico G. Glistenings in foldable intraocular lenses. J. Cataract Refract. Surg. 2002;28(7): 1211-1216.

8. Yoshida S, Matsushima H, Nagata M, Senoo T, Ota I, Miyake K. Decreased visual function due to high-level light scattering in a hydrophobic acrylic intraocular lens. Jpn. J. Ophthalmol. 2011;55(1):62-66.

9. Colin J, Orignac I. Glistenings on intraocular lenses in healthy eyes: effects and associations. J. Refract. Surg. 2011;27(12):869-875.

10. Christiansen G, Durcan FJ, Olson RJ, Christiansen K. Glistenings in the AcrySof intraocular lens: Pilot Study. J. Cataract Refract. Surg. 2001;27(5):728-733

11. Dhaliwal DK, Mamalis N, Olson RJ, et al. Visual Significance of glistenings seen in the AcrySof intraocular lens. J. Cataract Refract. Surg. 1996;22(4):452-457.

12. Gunenc U, Oner FH, Tongal S, Ferliel M. Effects on visual function of glistenings and folding marks in AcrySof intraocular lenses. J. Cataract Refract. Surg. 2001;27(10):1611-1614.

13. Minami H, Toru K, Hiroi K, Kazama S. Glistening of Acrylic Intraocular Lenses. RinshoGanka. Jpn J ClinOphthalmol. 1999;53(5):991-994.

14. Kim DH, James RH, Landry RJ, Calogero D, Anderson DJ, Ilev IK. Quantification of glistenings in intraocular lenses using a ballistic-photon removing integrating-sphere method. Appl. Opt. 2011;50(35):6461-6467.

15. Oshika T, Shiokawa Y, Amano S, Mitomo K. Influence of glistenings on the optical quality of acrylic foldable intraocular lens. Br. J. Ophthalmol. 2001;85(9):1034-1037.

16. Hayashi K, Hirata A, Yoshida M, Yoshimura MK, Hayashi H. Long-term effect of surface light scattering and glistenings of intraocular lenses on visual function. Am. J. Ophthalmol. 2012;154(2):240-251.

17. Mönestam E, Behndig A. Impact on visual function from light scattering and glistenings in intraocular lenses, a long-term study. Acta Ophthalmol. 2011;89(8):724-728.

18. Nagata N, Matsushima H, Mukai H, et al. Clinical evaluation of the transparency of hydrophobic acrylic intraocular lens optics. J. Cataract Refract. Surg. 2010;36(12):2056-2060.

19. van der Mooren M, Fransen L, Piers P. Effects of glistenings in intraocular lenses. Biomedical Opt Express. 2013;8(4):1294-1304.

20. Center for Devices and Radiological Health. Intraocular Lens Guidance Document.Silver Spring, MD: US Food and Drug Administration. Available from: http://www.fda.gov/OHRMS/DOCKETS/98fr/994052 gd. pdf. Accessed October 11, 2013. 


\section{Authors' reply}

\section{Brett E Thomes \\ Thomas A Callaghan}

Alcon Research Ltd (A Novartis Company), Fort Worth, TX, USA

Correspondence: Brett E Thomes

Alcon Research Ltd (A Novartis Company), 620I South Freeway,

Fort Worth, TX, USA

Tel + I 8175686429

Fax +I 8176153596

Email brett.thomes@alconlabs.com

\section{Dear editor}

This letter is in response to questions raised by Beiko and Grzybowski regarding our recent publication entitled "Evaluation of in vitro glistening formation in hydrophobic acrylic intraocular lenses". The formation of glistenings and their appearance depends upon many factors. The intraocular lens (IOL) material, processing, ocular disease, and measurement technique result in a variety of glistening behaviors reported in the literature. The Tognetto et $\mathrm{al}^{1}$ paper, referenced in both our recent publication and in Beiko and Grzybowski's letter, gives a good summary of various IOLs and supports the statement that glistenings within IOL materials are "typically" observed within a few months of surgery and plateau approximately 1 year after surgical implantation.

Our study uses an aggressive laboratory test method that is designed to purposely induce glistenings in a material to assess its propensity for forming glistenings. Our experimental method has been clearly described and permits comparison to historical values. The published laboratory test results demonstrate that manufacturing process improvements over the past 10 years have reduced the glistening response in current lenses (2012) compared to those manufactured in 2003. Manufacturing process changes have been reported to the appropriate regulatory agencies in accordance with applicable regulations. Alcon Research Ltd holds process changes and conditions as proprietary information.

The 5-year expiration date for the shelf life is primarily to ensure sterility of the product using real time testing. It is our contention that these dry, stored IOLs are no different than those implanted in eyes back in 2003. We have taken precautions by storing the IOLs in a controlled atmosphere of low moisture, protection from UV light, and limited temperature fluctuations that may impact glistening response. Our objective is to not artificially induce glistenings over the storage period. To assess glistening during storage, we have conducted internal laboratory bench studies to induce glistenings via extreme temperature and moisture fluctuations in the IOL. The storage conditions used for the 2003 IOLs fall well within the range where glistenings will not form.

The effect of glistenings on high spatial frequencies is not conclusive based on the published literature. ${ }^{1-5}$ In general, these studies suggest that the glistenings have no negative impact on contrast sensitivity at low or mid spatial frequencies. Two studies suggested possible effect of glistenings at high spatial frequencies. ${ }^{3,5}$ Gunenc et $\mathrm{al}^{3}$ used contrast sensitivity measurements based on in-house developed software, and require further study to confirm the results. The finding from the other study by Waite et $\mathrm{al}^{5}$ is not statistically significant. Miyata et $\mathrm{al}^{2}$ reported contrast sensitivity data at low, mid and high spatial frequencies for MA60BM, SA60AT, AR40, and Clarifllex patients. They didn't find any significant difference among the four groups at any spatial frequency. Christiansen et $\mathrm{al}^{6}$ found no correlation between glistening and contrast sensitivity. Colin and Orignac assessed glistenings in 97 eyes from 65 patients with AcrySof IOLs. ${ }^{4}$ They graded the glistenings level based on the slit lamp images. They found no correlation between the glistening grades and contrast sensitivity at any spatial frequencies $(3,6,12$, 18 cycles per degree), as well as no association with visual acuity.

There are several publications that address the effect of glistenings or light scattering on visual acuity (VA). ${ }^{1-7}$ Most of these published works concluded that VA does not degrade for the level of surface scattering due to clinically observed glistenings. The consensus among most published studies suggests that glistenings have no effect on best corrected visual acuity (BCVA)", even at the highest levels of clinical glistenings. ${ }^{1-7}$

In general, glistenings can increase the intraocular stray light. However, the total integrated light scatter measured is due to surface roughness and intraocular stray light. Every optical surface will have some degree of roughness, but our focus is to address intraocular stray light. The amount of intraocular stray light increase depends on the size and density of the glistening distribution. It is important to note that the stray light that would impact vision or retinal contrast is associated with forward light scatter, not with back light scatter. The de Waard et $a^{8}$ study suggests that forward light scatter, which may create disability glare, cannot be obtained from back light scatter measurements (such as Scheimpflug or slit-lamp images). Normative data of stray light values (Vos and van den Berg ${ }^{9}$ ) suggest that $\log (\mathrm{s})$ greater than $1.47 \mathrm{deg}^{2} / \mathrm{sr}$ represents serious stray light hindrance. van den Berg et $\mathrm{al}^{10}$ also studied disability glare in the aging eye, 
which suggested that stray light was considered to be impaired when there is a 3-fold increase in $\log (\mathrm{s})$ compared to the young eye. Das et $\mathrm{al}^{11}$ developed a technique to measure forward light scatter from new and artificially aged IOLs in the laboratory. They found that artificially aged IOLs had higher forward light scatter than new IOLs. The severely aged IOLs $\left(104\right.$ weeks at $80^{\circ} \mathrm{C}$, equivalent to $>40$ years at $35^{\circ} \mathrm{C}$ ) had stray light value of $\log (\mathrm{s})=1.108 \mathrm{deg}^{2} / \mathrm{sr}$, which is still lower than the $1.47 \mathrm{deg}^{2} / \mathrm{sr}$ serious stray light hindrance level from Vos and van den Berg. ${ }^{9}$ The same technique was used to measure forward light scatter in AcrySof Natural IOLs and stray light values were obtained. ${ }^{12}$ This study found that the stray light value for the 15 -year aged IOL is $0.4 \mathrm{deg}^{2} / \mathrm{sr}$, which is comparable to a young eye and well below the stray light hindrance value level of $\sim 1.47 \mathrm{deg}^{2} / \mathrm{sr}$. Thus, the visual impact for most clinically relevant cases appears insignificant, even though levels of back light scatter out of the eye may appear significant. ${ }^{4}$

\section{Disclosure}

Both authors are employees of Alcon Research, Ltd.

\section{References}

1. Tognetto D, Toto L, Sanguinetti G, Ravalico G. Glistenings in foldable intraocular lenses. J Cataract Refract Surg. 2002;28(7):1211-1216.

2. Miyata K, Otani S, Nejima R, et al. Comparison of postoperative surface light scattering of different intraocular lenses. Br J Ophthalmol. 2009;93:684-687.

3. Gunenc U, Oner FH, Tonal S, Ferliel M. J Cataract Refract Surg. 2001;27:1611-1614.

4. Colin J, Orignac I. Glistenings on intraocular lenses in healthy eyes: effects and associations. J Refract Surg. 2011;27:869-875.

5. Waite A, Faulkner N, Olson RJ. Am J Ophthalmol. 2007;144: $143-144$.

6. Christiansen G, Durcan FJ, Olson RJ, Christiansen K. J Cataract Refract Surg. 2001;27:728-733.

7. Nishihara $\mathrm{H}$, Yaguchi $\mathrm{S}$, Onishi T, Chida M, Ayaki M. J Cataract Refract Surg. 2003;29:1385-1388.

8. de Waard PW, Ijspeert JK, van den Berg TJ, de Jong PT. Intraocular light scattering in age-related cataracts. Invest Ophthalmol Vis Sci. 1992;33:618-625.

9. Vos JJ, van den Berg TJTP. CIE Collection. 1999;135:1-9.

10. van den Berg TJ, van Rijn LJ, Kaper-Bongers R, et al. Disability glare in the aging eye. Assessment and impact on driving. J Optom. 2009;2:112-118.

11. Das K, et al. A Technique for Measuring Forward Light Scatter in Intraocular Lenses. J Cataract Refract Surg. 2013;39.

12. Das, et al. 2013 ARVO Presentation, Seattle, WA.
Clinical Ophthalmology

\section{Publish your work in this journal}

Clinical Ophthalmology is an international, peer-reviewed journal covering all subspecialties within ophthalmology. Key topics include: Optometry; Visual science; Pharmacology and drug therapy in eye diseases; Basic Sciences; Primary and Secondary eye care; Patient Safety and Quality of Care Improvements. This journal is indexed on

Submit your manuscript here: http://www.dovepress.com/clinical-ophthalmology-journal

\section{Dovepress}

PubMed Central and CAS, and is the official journal of The Society of Clinical Ophthalmology (SCO). The manuscript management system is completely online and includes a very quick and fair peer-review system, which is all easy to use. Visit http://www.dovepress.com/ testimonials.php to read real quotes from published authors. 